\title{
Memoria del coronel Ezequiel Apodaca: entre Canchas Blancas y el singani como bebida nacional*
}

\section{Remembrances of Colonel Ezequiel Apodaca: Between Canchas Blancas}

\author{
and 'Singani' as a national liquor
}

\author{
Aldo Garrido** \\ Pablo Lacoste ${ }^{* * *}$
}

Instituto de Estudios Avanzados (IDEA), Universidad de Santiago de Chile, Chile.

\begin{abstract}
Resumen
Este artículo examina críticamente el libro Memoria del coronel Ezequiel Apodaca (1880), publicado en 2017 en un contexto de fuerte polémica. El objetivo principal es establecer la autenticidad del texto. Se detecta que la parte principal (diario del oficial boliviano) es verosímil, no así un texto complementario (el Parte de Lino Morales), el cual parece falso. Sobre esta base se concluye que no hay evidencia para sostener la
\end{abstract}

\footnotetext{
"Este artículo fue elaborado en el marco del proyecto sobre "patrimonio agroalimentario", número 031894LG, financiado por la Dirección de Investigación Científica y Tecnológica (DICYT) de la Vicerrectoría de Investigación, Desarrollo e Innovación (VRIDEI) de la Universidad de Santiago de Chile. Los autores desean agradecer al doctor Sergio Molina por conseguir la Memoria del coronel Apodaca.

*** Magíster en Estudios Internacionales y doctorando en Estudios Americanos, Universidad de Santiago de Chile (USACH). Román Díaz 89, Providencia, Santiago de Chile. Correo electrónico: aldo.garrido.quiroz@gmail.com. ORCID: https://orcid.org/0000-0003-2504-2955

*** Licenciado en Historia y doctor en Historia, Universidad de Buenos Aires. Doctor en Estudios Americanos, Universidad de Santiago de Chile (USACH), y profesor de esta misma casa de estudios. Román Díaz 89, Providencia, Santiago de Chile. Correo electrónico: pablo.lacoste@usach.cl. ORCID: https://orcid.org/0000-0003-1876-8141
}

Cómo citar este artículo: Garrido, A. y Lacoste, P. (2020). Memoria del coronel Ezequiel Apodaca: entre Canchas Blancas y el singani como bebida nacional. Si Somos Americanos. Revista de Estudios Transfronterizos, 21(1), 180-201. doi: 10.4067/S0719-09482021000100180 
tesis de Canchas Blancas como batalla importante, pero la fuente auténtica brinda aportes relevantes acerca de otros temas, como por ejemplo, el patrimonio agroalimentario. Entre otras contribuciones, este documento muestra los orígenes del singani como bebida nacional de Bolivia, lo cual representa un antecedente de importancia para comprender la evolución de los destilados andinos de América del Sur.

Palabras clave: Guerra del Pacífico, batalla de Canchas Blancas, patrimonio agroalimentario latinoamericano.

\begin{abstract}
This article offers a critical analysis of the book Remembrances of Colonel Ezequiel Apodaca (1880), which was published in 2017 in a context of significant controversy. The main objective is to ascertain the authenticity of the text. We establish that the main part (diary of a Bolivian official) is plausible, but not a complementary text (written by Lino Morales), which appears to be false. We thus conclude that there is no evidence to support the thesis of Canchas Blancas as being an important battle. However, the authentic source does provide important contributions on other issues, such as agricultural-food heritage. For example, this document shows the origins of Singani which has become one of Bolivia's national liquors, providing important historical background that contributes to our understanding of the evolution of Andean distilled liquors in South America.
\end{abstract}

Keywords: War of the Pacific, Battle of Canchas Blancas, Latin American Agri-Food Heritage.

\title{
Introducción
}

Con las siguientes palabras: "Los grandes acontecimientos profundamente decisivos en la vida de los pueblos generan rica cosecha de memorias", Bauer ([1957] 1970, p. 432) ha llamado la atención sobre la fecundidad de los diarios, crónicas y fuentes afines que se producen en contextos extraordinarios, particularmente en tiempos de guerra. Estas fuentes enriquecen los estudios históricos en asuntos políticos, económicos, sociales y culturales, incluyendo aspectos de creciente interés como el patrimonio agroalimentario, tal como muestran los textos de Atkinson (2014 y 2016). Para el caso de América Latina, las obras producidas en la guerra de la Independencia han permitido conocer los orígenes de productos como las longanizas de Chillán, el chacolí, el vino asoleado, el queso de Tafí del Valle y el valdiviano (Carrera, 1900; Espejo ([1878] 1916); Lacoste et al., 2015; Lacoste, 2017; Pueyrredón, [1863] 1947). A su vez, las memorias producidas por la Guerra del Pacífico han facilitado la visibilización del pisco (Lacoste, 2018; Parvex, 2014), contribuyendo así al conocimiento de los antecedentes históricos que en los últimos años han adquirido cada vez más relevancia para el proceso de construcción 
del valor simbólico, identitario y patrimonial de alimentos y bebidas (Cofré y Stewart, 2020; Goméz, Delgado y Palmas, 2020; Sequeira y Montes Leal, 2020; Togores, Parga Dans y Diz, 2020). A ello se podrían añadir otros temas que se han enriquecido a partir de las memorias y diarios producidos en situación de guerra. De allí el interés por la reciente publicación de Memoria del coronel Ezequiel Apodaca ([1880] 2017), ${ }^{1}$ diario de un oficial boliviano escrito durante la Guerra del Pacífico, el cual se mantuvo inédito durante 137 años.

La valoración académica de esta nueva fuente rescatada para la historiografía se vio empañada porque el anuncio de su publicación se focalizó exclusivamente en los aspectos militares. El gobierno de Evo Morales concentró el foco de atención en la batalla de Canchas Blancas y la presentó como una gran victoria de las fuerzas bolivianas en esa guerra. Para ampliar su visibilidad, ordenó su teatralización al Ejército de Bolivia. ${ }^{2}$ También aprovechó la oportunidad para apoyarse en esta obra con el fin de fundamentar su estrategia general de modificar la política exterior de Bolivia a partir de la crítica al enfoque tradicional de las élites bolivianas. El énfasis en ese hecho de armas llevó a investigadores históricos de Perú y Chile a refutar a Evo Morales y negar toda verosimilitud respecto del citado hecho de armas.

La edición llevada a cabo por parte del Ministerio de Defensa de Bolivia de Memoria del coronel Ezequiel Apodaca en 2017 generó fuertes polémicas en el ámbito de la historia y de las relaciones internacionales, en el cual participaron autoridades de los tres países involucrados: en Perú se destacó la voz de Parodi (23 de abril de 2018), en un texto periodístico, mientras que en Chile la tesis fue duramente cuestionada por Pelayo (2019), quien estudió el itinerario vital de los más de 80 mil chilenos enrolados en el conflicto y descartó la verosimilitud de la tesis de Canchas Blancas como batalla relevante. Sin embargo, este autor no se expidió sobre la autenticidad de la citada Memoria.

El presente artículo tiene como objetivo examinar críticamente el libro publicado en 2017 con vistas a determinar su grado de verosimilitud y su valor como fuente auténtica, para identificar luego sus aportes más significativos. Para avanzar en esa dirección, se han tenido en cuenta las recomendaciones de Bauer (1970) y Atkinson (2014, 2016). El primero recomienda tensionar el texto a la luz de la evidencia documental producida en la época, para detectar eventuales contradicciones, anacronismos e inconsistencias. Por su parte el segundo, a partir de su experiencia en la historia bélica, aporta criterios para observar críticamente las fuentes escritas en el fragor del combate. Entre otros elementos, Atkinson detecta que las fuentes producidas durante situaciones de guerra pueden generar distorsiones, a la vez que también

\footnotetext{
${ }^{1}$ Cabe consignar que el título exacto del libro emplea la abreviatura "Cnl." en lugar de la palabra “coronel”, y su título completo es Memoria del Cnl. Ezequiel Apodaca. Potosí-Cotagaita-Camino a Canchas Blancas 1879-1880.

2 "Hoy rememoramos la Batalla de Canchas Blancas, en la que 500 soldados de la Quinta División, junto a campesinos e indígenas, derrotaron a 1.400 soldados del ejército chileno. Esa gesta heroica frustró el plan de Chile, de tomar por las armas las minas de Potosí" (Morales, 28 de marzo de 2018).
} 
visibilizan aspectos de la vida humana que los documentos oficiales no atienden con interés, como la comida, la bebida y el patrimonio agroalimentario (Atkinson, 2014, 2016).

Este artículo se propone también dos objetivos secundarios: primero, establecer si existió la batalla de Canchas Blancas, tal como afirmó el gobierno de Evo Morales; segundo, detectar si la fuente entrega otros datos relevantes para la historia latinoamericana, particularmente en lo que concierne al patrimonio agroalimentario.

Como hipótesis de trabajo, este estudio sostiene que el diario de Apodaca sí puede considerarse auténtico y, por lo tanto, merece ser incorporado al corpus documental de la Guerra del Pacífico, junto con ser reconocido como una fuente valiosa para el análisis de diversos temas de la historia latinoamericana.

\section{Discusión bibliográfica}

Los editores del diario de Apodaca han destacado que esta obra puede cambiar radicalmente la percepción sobre las fuerzas bolivianas en la Guerra del Pacífico, al presentar un testimonio positivo que pueda revertir la imagen adversa construida por la historiografía tradicional. En efecto, los textos dedicados al tema han apelado a la notable debilidad militar boliviana, cuyos soldados eran escasos, "descalzos, sin alimentos ni abrigos" (Lora, 1981, p. 141). Su ejército carecía de instrucción, de vestuario y aun de armas (Paz Soldán, 1884). "Mal armados, sin uniformes ni calzado, (las tropas bolivianas) supieron batirse con denuedo -sobre todo en el Alto de la Alianza- pero pronto abandonaron la guerra" (López Martínez, 1989, p. 22). Otro autor fue más allá: "Bolivia fue la causa principal de la guerra del Pacífico; pero su acción poco o nada se dejó sentir en los campos de batalla" (Caivano, 1886, p. 5). El recurrente relato de la historiografía peruana culminó por construir un imaginario signado por la minimización del valor y la capacidad militar de Bolivia en la guerra. En cierto modo, Perú apeló a este argumento para explicar, al menos parcialmente, su derrota.

Paradójicamente, el diario de Apodaca fue ignorado por la corriente principal de historiografía de la Guerra del Pacífico, tanto en Chile como en Perú y Bolivia. Los autores chilenos no la mencionan (Barros Arana, 1880; Benavides Santos, [1927] 1972; Concha, 2007, Eyzaguirre, 1963; Gutiérrez, Gómez y Guerrero, 1981; Ibarra, 2017; Lagos Carmona, [1966] 1981; Parvex, 2014; Pelayo, 2019; Ríos Gallardo, 1963; Ruz, 1980) y los peruanos han asumido la misma actitud (Caivano, 1886; Cam, 2017; Choque Alanoca, 1998; López, 1980; López Martínez, 1989; Lora, 1981; Paz Soldán, 1884). Lo mismo puede decirse de la corriente principal de la historiografía boliviana (Escobari Cusicanqui, 1975; Gutiérrez, 1914; Guzmán Escobari, 2015; Zambrana e Inarra, 2011).

Al anunciar la edición del libro, el gobierno de Bolivia afirmó que esa invisibilización era parte de una estrategia general de ocultamiento de aspectos importantes de la guerra para favorecer a los grupos vinculados al poder tradicional de Bolivia, por lo que con 
esta publicación esperaba brindar un aporte al conocimiento de la historia. Sin embargo, hubo una obra que vino a romper esta tendencia general de ignorar el diario de Apodaca como fuente: el libro de Querejazu (1979), que lo tuvo entre sus fuentes y le brindó un sugerente tratamiento.

\section{El libro y su contenido}

En primer lugar, conviene aclarar el contenido de la obra publicada por el gobierno de Bolivia, puesto que este volumen incluye varios documentos de distintos autores. Ello complejiza el análisis crítico para ponderar su verosimilitud y autenticidad, siguiendo las recomendaciones de Bauer ([1957] 1970) y Atkinson (2014, 2016). En efecto, el diario que escribió Apodaca entre julio de 1879 y abril de 1880 representa el documento principal del libro (pp. 19-66). Asimismo, este contiene el estudio preliminar escrito recientemente por el coronel Edmundo Sanabria Morales (pp. 3-17). Posteriormente incluye las "Notas del Escuadrón Méndez", dedicadas a la unidad de caballería que integró la $5^{\text {a }}$ División del Ejército Boliviano durante la Guerra del Pacífico (pp. 69-71); el "Parte del Coronel Lino Morales de la batalla de Canchas Blancas" (pp. 72-78) y la lista de nombres de oficiales y de efectivos de tropa que formaron parte de esa acción militar (pp.79-134). Desde el punto de vista del contenido, los dos documentos más relevantes son el diario de Apodaca y el "Parte" de Lino Morales. Por lo tanto, en ellos conviene focalizar el análisis crítico.

Existen diferencias sugerentes entre los textos de Apodaca y Lino Morales. La memoria del primero es, en realidad, un diario en el cual el jefe de Estado Mayor registró las percepciones, diálogos, reflexiones y hechos acaecidos durante la campaña. Contiene conversaciones entre camaradas, descripciones acerca de sensaciones de hambre y frío, y observaciones sobre comidas, bebidas y patrimonio agroalimentario. También registra rumores y versiones que circulan en un campamento militar aislado, a partir de relatos aportados por indios, viajeros, espías, comerciantes y demás. En cambio, el texto de Lino Morales es exclusivamente el "parte" de la batalla de Canchas Blancas, en el cual se enumeran los objetos capturados, cuyo registro arroja 890 fusiles, 7 cañones, 25 barriles de pólvora, 1.120 equinos y miles de folletos de propaganda para promover agitación política. También informa sobre abultadas bajas enemigas, incluyendo 330 muertos y 400 heridos. Estas cifras no son confirmadas en el diario de Apodaca, quien no entrega ninguna precisión numérica sobre objetos ni se refiere a la cantidad de tropas intervinientes; tampoco menciona bajas ni la captura de armamento; por el contrario, Apodaca afirma que solo se recogieron despojos sin importancia. Pero este diario sí entrega un dato relevante para el análisis, la hora del hecho de armas: el enfrentamiento se produjo a las veinte horas, en la oscuridad de la noche. 


\section{La Memoria y el "Parte" antes de su publicación (2017)}

Siguiendo las recomendaciones de Bauer ([1957] 1970), para ponderar la autenticidad de un documento conviene examinar su propia historia, pues por este camino se pueden detectar indicios relevantes. La primera noticia de la existencia de la Memoria del Cnl. Ezequiel Apodaca surgió a fines de la década de 1960. Según explica el coronel Morales en el estudio preliminar, en esos años se realizaron en Bolivia unas conferencias para visibilizar la batalla de Canchas Blancas. Poco después, un grupo de intelectuales se propuso difundir la sensacional noticia de la victoria de las armas bolivianas en la batalla de Canchas Blancas. Los mentores se organizaron en el "Comité Nacional Pro Reivindicación Histórica”, y lanzaron un plan de acción para visibilizar el testimonio de Apodaca. Entre fines de 1971 y comienzos de 1972, durante el gobierno de facto del general Hugo Banzer, el citado comité realizó encuentros, actividades y declaraciones públicas para reivindicar la victoria de la batalla de Canchas Blancas.

La comunidad intelectual de Bolivia recibió esta tesis con cierto escepticismo. Sobre todo porque dicho comité no logró acompañar el documento con otra evidencia, como por ejemplo, restos materiales en el lugar, sepulturas, etc. Además, se confirmó que la citada batalla no figuraba en los partes militares que, de acuerdo a los usos y costumbres de la época, se redactaban después de cada hecho de armas. Al no disponerse de evidencia, la prensa de la época censuró severamente la tesis de la batalla de Canchas Blancas (El Litoral, 23 de marzo de 1972).

Estos antecedentes sirvieron para visibilizar la fuente hasta entonces ignorada por los historiadores. Aceptó este desafío Roberto Querejazu Calvo, destacado historiador, abogado y diplomático boliviano, con experiencia directa en escenarios bélicos (veterano de la Guerra del Chaco). Buena parte de su vida la dedicó a la historia y elaboró numerosos artículos y libros sobre su país, particularmente sobre las guerras del Pacífico y del Chaco. Su enjundiosa obra le permitió recibir el Premio Nacional de Cultura (2000) y la condecoración "Cóndor de América" (2006), otorgada por el presidente Carlos Mesa. Estos antecedentes son relevantes porque antes que Evo Morales, Querejazu ya había detectado y valorado las Memorias de Apodaca como fuente auténtica; así lo reflejó en su libro Guano, salitre, sangre: historia de la Guerra del Pacífico (La participación de Bolivia), publicado en 1979 y reeditado varias veces. Esta obra es, probablemente, la más completa versión del conflicto elaborada por un autor boliviano.

Los dos documentos principales publicados en la edición de 2017 recibieron tratamientos distintos en la obra de Querejazu (1979). Por un lado, el diario de Apodaca fue positivamente considerado como fuente legítima y citado en varios pasajes de su obra (pp. 367-368). En cambio, el autor no brindó crédito al "Parte" de Lino Morales. Este documento fue juzgado inverosímil por el historiador boliviano y no lo tuvo en cuenta como fuente histórica. Querejazu no apoyó la tesis de la batalla de Canchas Blancas como gran victoria boliviana. Más adelante, en otra obra dedicada a comparar la participación de Bolivia en sus dos grandes guerras, titulada Guerras del Pacífico y 
del Chaco. Similitudes y diferencias (1982), el autor se expresó con claridad: "en la Guerra del Pacífico las tropas bolivianas participaron en cinco combates: Calama, Tambilllo, Pisagua, San Francisco y el Alto de la Alianza (Tacna), e intervención del batallón Loa en la acción de Tarapacá" (Querejazu, 1982, p. 24). Por lo tanto, para este historiador boliviano no hubo tal batalla de Canchas Blancas. Por lo tanto, este primer análisis inclina a pensar que el diario de Apodaca ya cuenta con antecedentes que apoyan su autenticidad, no así el "Parte" de Lino Morales.

Algo parecido ocurre con el enfoque de Atkinson (2014), quien aporta otro criterio para ponderar la credibilidad de los partes de batalla: la hora. De acuerdo con este autor, que se apoya también en la experiencia del general Patton, los partes de hechos de armas ocurridos después de oscurecer son inexorablemente exagerados y, por lo tanto, siempre se tienen que interpretar con precaución (Atkinson, 2016, p. 17). Este fue el caso del "Parte" de Morales, dedicado a informar sobre acciones de combate que ocurrieron después de las ocho de la noche. Es por esto que la mirada crítica recomienda el mismo camino que recorrió la historiografía boliviana con relación a este documento. El "Parte" de Lino Morales tiene que tomarse con reservas.

\section{El hecho de armas de Canchas Blancas en su contexto histórico}

La localidad de Canchas Blancas se encuentra a $470 \mathrm{~km}$ al nordeste del puerto de Antofagasta. Para ponderar la verosimilitud de una batalla en ese lugar, conviene examinar los sucesos en el teatro de operaciones en la etapa inmediatamente anterior a la fecha. Ello comprende el periodo de nueve meses, que va desde el desembarco chileno en Antofagasta (14 de febrero de 1879) hasta la presunta batalla (12 de noviembre de 1879). Dentro de ese lapso, es necesario examinar los movimientos de tropas en el terreno para examinar la situación en la que se encontraban chilenos y bolivianos en el momento del citado encuentro.

Al estallar la Guerra del Pacífico, la fuerza del ejército chileno fluctuaba entre dos mil y dos mil doscientos hombres (Bulnes, 1911, p. 183; Gutiérrez et al., 1981, p. 21). Una vez iniciada la contienda se aceleraron los procesos de reclutamiento e instrucción. En febrero de 1879 el ejército chileno desplegó en la ciudad de Antofagasta dos mil efectivos. Después de la declaración de guerra de Bolivia a Chile (1 de marzo de 1879), el ejército chileno avanzó hacia el nordeste y llegó a Caracoles. Allí el coronel Emilio Sotomayor organizó la unidad encargada de ocupar Calama, compuesta por 544 soldados y dos piezas de artillería (Bulnes, 1911, pp. 174-179; Gutiérrez et al., 1981, p. 72). La acción fue realizada por el $4^{\circ}$ de Línea, con caballería y dos piezas de artillería. Esta fuerza ocupó Calama el 23 de marzo y en la acción perdió la vida Eduardo Abaroa Hidalgo, héroe civil boliviano en la Guerra del Pacífico. La mayor parte de la población boliviana huyó hacia el este, atravesando las ásperas y desiertas altiplanicies. Varios vecinos se refugiaron en la villa de San Cristóbal, situada junto a Canchas Blancas, a 250 km de Calama (Apodaca, [1880] 2017, pp. 37-38; Querejazu, 1979, p. 356). 
La campaña por el control del Departamento Litoral se completó con la ocupación de las restantes localidades hasta entonces bolivianas. Entre ellas las más importantes fueron San Pedro de Atacama (100 km al sureste de Calama) y San Francisco de Chiu Chiu (35 km al nordeste de Calama). La localidad de Chiu Chiu estaba ya a $215 \mathrm{~km}$ al sudeste de Canchas Blancas. Con el control y ocupación militar de estas localidades, el ejército de Chile formó la llamada "Línea del Loa", que tenía como objetivo asegurar el dominio chileno en el antiguo Departamento del Litoral de Bolivia (Bulnes, 1911, p. 179). Para los militares chilenos, la Línea del Loa estaba "destinada a impedir que el ejército boliviano bajara hacia el Litoral, concretamente en dirección a Antofagasta" (Gutiérrez et al., 1981 p. 75).

La seguridad del Departamento del Litoral era vital para la estrategia chilena, en vísperas de su enfrentamiento directo con Perú. De todos modos, los análisis de la época descartaban una invasión boliviana por ese lugar. La única posibilidad sería con un ejército boliviano organizado en Potosí que avanzara desde allí hacia Calama. Pero el alto mando chileno juzgaba que, por las características del terreno, entre el desierto y la altura (más de $4.000 \mathrm{msnm}$ ), era imposible desplazar por ese lugar a un ejército con miles de tropas. Así lo expresó el presidente Pinto al ministro de Guerra, coronel Saavedra:

Considero imposible la venida de un ejército del interior de Bolivia habiendo en el litoral fuerzas enemigas en Calama o Chiu Chiu. La naturaleza del camino que tendrían que atravesar, considero de todo punto imposible la traslación por ese camino de un ejército reunido por escasa que sea su fuerza. (Pinto cit. en Bulnes, 1911, pp. 180-181)

Para el Estado Mayor de Chile, con solo desplazar pequeñas unidades separadas unas de otras bastaba para que una mínima fuerza de seguridad pudiera derrotar a las tropas bolivianas. Por este motivo, las fuerzas acantonadas en la Línea del Loa nunca superaron los setecientos efectivos. 
Figura $\mathrm{N}^{\circ}$ 1: Línea del Loa y maniobras de la $5^{\text {a }}$ División de Bolivia

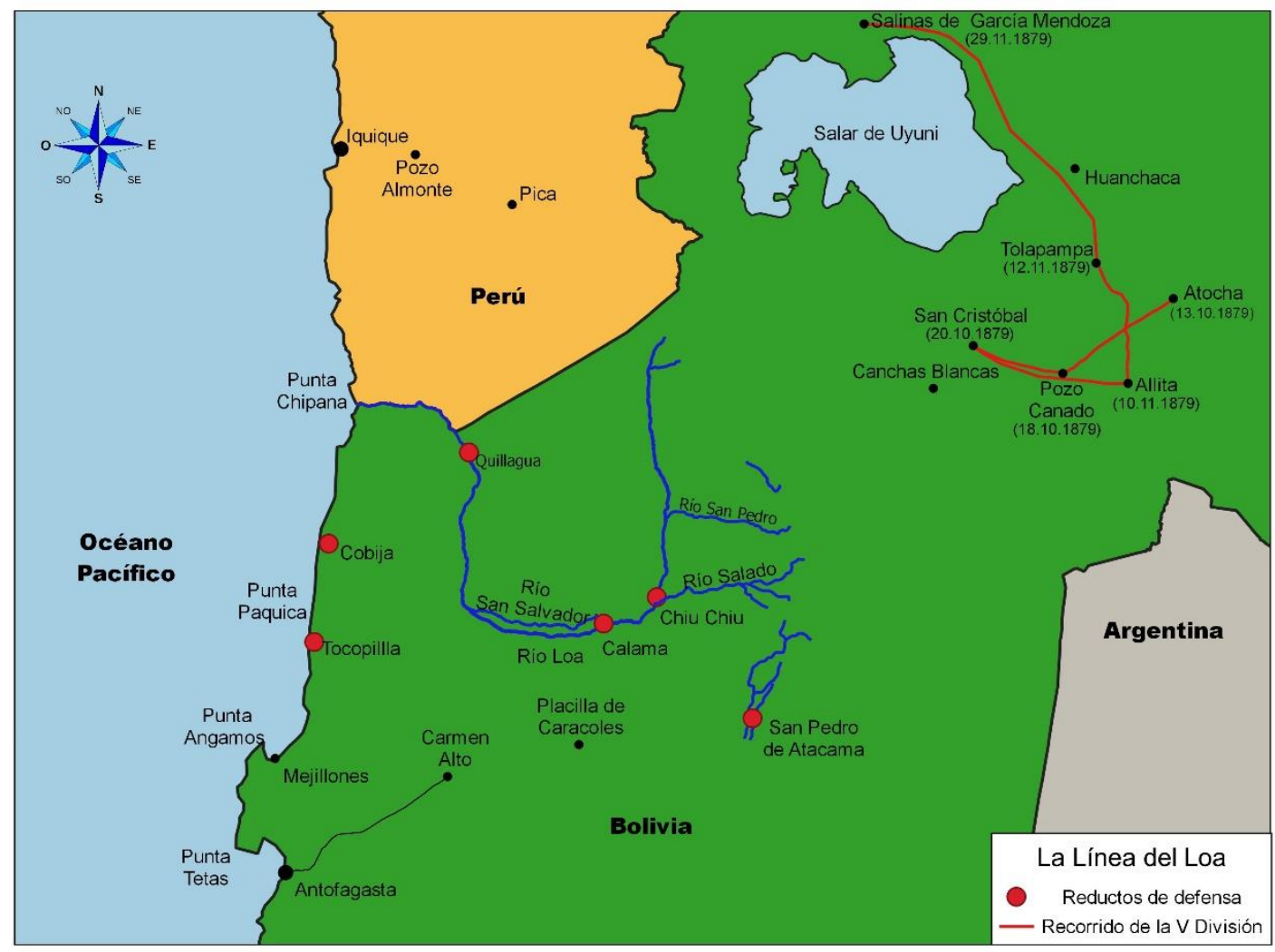

Fuente: elaborado por Aldo Garrido a partir de datos publicados originalmente por Bulnes (1911).

Poco después de la ocupación del litoral boliviano, el gobierno de Chile declaró la guerra al Perú (5 abril de 1879). Consiguientemente, en breve comenzaron los enfrentamientos navales entre las marinas de Chile y Perú. La captura del monitor Huáscar en la batalla de Angamos (8 de octubre de 1879) resolvió el duelo en favor de Chile. A partir de entonces, las fuerzas chilenas comenzaron a trazar su nuevo objetivo estratégico: la ocupación del departamento de Tarapacá (Perú). Este territorio se convirtió en el teatro de operaciones de la segunda campaña del ejército de Chile y en el centro de su atención. En este nuevo escenario, las fuerzas chilenas aprovecharon la supremacía naval y el control del departamento de Antofagasta para preparar la invasión a Tarapacá. Las tropas se trasladaron en la flota desde los puertos de Valparaíso, Talcahuano y Coquimbo hasta Antofagasta. Allí se reunieron diez mil hombres, con vistas a su posterior envío hacia Pisagua para ocupar Tarapacá (Mellafe y Pelayo, 2016, p. 228).

Las tropas chilenas desplegadas en el interior del Departamento del Litoral asumieron papeles secundarios. La principal guarnición se estableció en Calama. Tras ser conquistada por cerca de seiscientos efectivos, las fuentes chilenas afirman que su dotación se redujo a 380 (Ruz, 1980, p. 131); sin embargo, las fuentes bolivianas de la época sostienen que mantuvo la dotación original de seiscientos soldados, tal como consignó el coronel Carrasco en el parte de la batalla de Tambillo (Carrasco, 1879, p. 13). San Pedro de Atacama se protegió con cuarenta soldados (veinte jinetes de 
caballería y veinte infantes) (Parvex, 2014, p. 50). Las guarniciones militares instaladas en Calama, Chiu Chiu y San Pedro de Atacama se destinaron a asegurar los puntos estratégicos y de abastecimiento (Sanhueza y Gundermann, 2009, p. 225).

Mientras tanto, el ejército boliviano realizaba sus preparativos. El general Daza marchó desde La Paz hacia Tacna con cuatro divisiones para reunirse allí con sus aliados peruanos. La seguridad del litoral quedó en manos del general Narciso Campero, a cargo de la $5^{\text {a }}$ División (Bulnes, 1911, p. 166). Su jefe de Estado Mayor era el coronel Exequiel Apodaca. Contaba con el escuadrón de caballería "Méndez" de 140 jinetes y cuatro batallones de quinientas efectivos cada uno: "Bustillo", "Ayacucho", "Tarija" y "Chorolque". Se compraron trescientos fusiles Remington a un traficante argentino, junto con pólvora y municiones. La misión de la $5^{\text {a }}$ División era desplazarse por la cordillera de los Andes, cerca de San Pedro de Atacama, Calama y Canchas Blancas, para concurrir al campo de batalla en el lugar preciso. La ruta implicaba recorrer montañas desiertas a una altura aproximada de 4.000 metros.

Los proveedores dilataron la entrega de los abastecimientos, lo cual demoró la partida de la $5^{\text {a }}$ División hacia el teatro de operaciones. Esta permaneció en Cotagaita durante un largo periodo de tiempo. En efecto, ocho meses después de iniciada la guerra, Campero todavía permanecía en Cotagaita, $170 \mathrm{~km}$ al sur de Potosí, sin poder salir de campaña. Mientras tanto se fortalecían las conspiraciones políticas. Campero se sumó al grupo que pretendía derrocar a Daza, idea compartida por otros oficiales. Pero algunos jefes de la $5^{\text {a }}$ División permanecían leales al presidente, entre ellos, los coroneles Morales, Estensoro y Apodaca. Esta diferencia política melló las confianzas, y condujo a Campero a tomar distancias de los tres coroneles. Con estas fisuras internas, la $5^{\mathrm{a}}$ División recién se puso en marcha hacia el teatro de operaciones el 11 de octubre de 1879.

Mientras tanto, en el departamento de Antofagasta, las fuerzas chilenas realizaban movimientos para consolidar sus posiciones. Las tropas asentadas en Calama efectuaron incursiones hacia el interior, siguiendo la ruta de las antiguas postas del camino que comunicaba con Huanchaca y Potosí, con el objeto de interceptar el tráfico de abastecimiento de los ejércitos boliviano y peruano, y de infundir temor en la población local (Sanhueza y Gundermann, 2009). Una de estas excursiones se extendió, justamente, hasta Canchas Blancas el 4 de setiembre de 1879:

El activo jefe, comandante de armas de Calama don José María $2^{\circ}$ Soto, creyó oportuno recorrer la línea de operaciones con el objeto de inutilizarla al enemigo, dado caso de que éste pretenda expedicionar por ahí. Al efecto, movilizó un piquete de 25 cazadores y otros tantos paisanos y con ellos comenzó una correría de 36 días por esos apartados lugares. El teniente don Ramón Varas rechazaba a 50 y más bolivianos que oponían resistencia en las postas de Tapaquilche y Viscachilla, despejando el trayecto hasta que ocupó Canchas Blancas. Como resumen de esta excursión, he aquí la lista de los animales, carretas, víveres, forraje y armas quitados en las postas de Canchas Blancas, Viscachilla y Tapa Quilcha, con más de 5 muertos, por parte del enemigo. (Boletín de la Guerra del Pacífico, 1879-1881, 1979, p. 327). 
La incursión significaba una penetración de $250 \mathrm{~km}$ en territorio enemigo y demostró que Canchas Blancas estaba dentro del radio de acción efectiva de las fuerzas chilenas asentadas en Calama. Las fuerzas involucradas fueron mínimas: solo participaron 25 cazadores y algunos paisanos como personal de apoyo; estos se encontraron con un número también menor de bolivianos, a los cuales rechazaron. La excursión fue bastante prolongada (más de un mes) y solo tenía como objetivo prevenir y observar desplazamientos de tropas enemigas.

En el Estado Mayor de Bolivia, la presencia chilena en Canchas Blancas a comienzos de septiembre fue interpretada como una amenaza de penetración en el país, posiblemente dirigida hacia la mina de plata de Huanchaca. A través del desierto, los rumores y noticias exageradas circulaban con fuerza, causando alarma. El 2 de septiembre, Apodaca escribió en su diario: "llegaron de la región de Canchas Blancas indios con noticias importantes. Los chilenos están en plenos preparativos para llegar a Potosí. El comandante, además, recibió una comunicación de un boliviano confirmando todo esto" (Apodaca, [1880] 2017, p. 29).

La situación era preocupante porque mientras los chilenos recorrían el territorio, la $5^{\mathrm{a}}$ División, encargada de la seguridad del Litoral, seguía inmovilizada en Cotagaita, 180 $\mathrm{km}$ al este de Canchas Blancas. El presidente Daza había ordenado reiteradamente a Campero ponerse en marcha, pero este se había negado, alegando la falta de suministros. Pero después de la incursión chilena a Canchas Blancas, Daza consideró que ya no podía tolerarse por más tiempo la demora de Campero, y le envió enérgicos mensajes. "La responsabilidad de la ocupación chilena de Canchas Blancas recae exclusivamente sobre usted. Evite usted el progreso de las operaciones del enemigo y muy especialmente la ocupación de Huanchaca" (Querejazu, 1979, p. 353), le escribió el 5 de septiembre. Dos días más tarde, Daza le mandó un nuevo mensaje: "Conviene que al menos ocupe Canchas Blancas, desde donde procurará proteger las comunicaciones con la República Argentina. Además, hará adelantar sus avanzadas hasta Santa Bárbara y extenderá espionaje hasta Calama y la línea del Loa" (Querejazu, 1979, p. 353). El presidente Daza parecía particularmente obsesionado con Canchas Blancas y, diez días más tarde, el 18 de septiembre, insistió: "Una vez ocupadas las importantes posiciones de San Cristóbal y Canchas Blancas, conviene que concentra allí todas las provisiones que puedan obtenerse, sin omitir sacrificio alguno, y estar listo para tomar la ofensiva marchando sobre Calama" (Querejazu, 1979, p. 353).

La marcha de la $5^{\text {a }}$ División comenzó, por fin, el 11 de octubre. La campaña fue anotada por dos cronistas, Manuel Alba y Exequiel Apodaca; el primero era aliado político y amigo de Campero, no así el segundo, como se ha explicado. Después de cuarenta días de marchas por el desértico altiplano, las tropas llegaron a la localidad de San Cristóbal, muy cerca de Canchas Blancas, a 4.113 metros de altitud. Allí encontraron bolivianos oriundos de Calama que habían huido ante la llegada de las tropas chilenas. El pueblo era "una pequeña población de indios, rodeada de cerros. Más fría que Potosí, con un viento constante que arrastra gran cantidad de arena. Solo tiene dos calles mal empedradas. La iglesia, de buenas dimensiones, tiene hermosos cuadros" (Querejazu, 1979, p.356). 
La estadía de la $5^{a}$ División en San Cristóbal se hizo dolorosa e incómoda. Los alimentos eran insuficientes y se vivía un ambiente de desconcierto. Un grupo de bolivianos llegó desde Calama, y trató de persuadir a Campero de reconquistar esa ciudad, asegurando el apoyo de parte de la población local. Sin embargo, la idea no fue aprobada. Tras 16 días de permanencia en el lugar, se resolvió dividir las fuerzas. El cuerpo principal, a órdenes de Campero, con sus oficiales de confianza y tres batallones, inició macha hacia el norte. En cambio, los coroneles menos afectos al comandante recibieron órdenes de permanecer en el lugar junto al escuadrón de caballería Méndez y el batallón Ayacucho. Allí continuaron Apodaca, Lino Morales y Ayoroa, los leales al presidente Daza y opuestos a su derrocamiento. Desde el punto de vista de las crónicas, también se produjo una división: la $5^{\text {a }}$ División marchó con Campero hacia el norte, mientras Apodaca quedó como testigo de las fuerzas que quedaron en San Cristóbal.

La partida del cuerpo principal de la $5^{\text {a }}$ División fue registrada por el doctor Manuel V. Alba, quien marchó junto a Campero en razón de su cercanía política e intimidad personal. La fuerza avanzó en dirección al nordeste. Tras recorrer penosamente $140 \mathrm{~km}$, el 12 de noviembre alcanzaron el pueblo de Tomave. Luego cambiaron el rumbo hacia el noroeste, y después de recorrer otros $130 \mathrm{~km}$, el 29 de noviembre llegaron a Salinas García Mendoza. Allí viraron hacia el nordeste y avanzaron otros $100 \mathrm{~km}$ hasta llegar a Huari, junto al lago Popó (16 de diciembre). La marcha se caracterizó por la constante llegada de noticias funestas sobre los hechos bélicos y las derrotas tanto en batallas navales como terrestres. Ello servía para deteriorar la moral de la tropa y agravaba el sufrimiento causado por insuficiente alimento y vestido; varios soldados murieron de frío; otros enloquecieron. La llegada de soldados dispersos de la batalla de San Francisco agudizaba el ambiente pesimista de las tropas. Posteriormente recibieron una contraorden de Daza: la $5^{\text {a }}$ División debía volver sobre sus pasos y regresar hacia el sur por la vía de Tomave, para luego alcanzar de nuevo Canchas Blancas y desde ahí lanzarse sobre Calama para recuperarla. Hasta allá se dirigió Campero, con la ilusión de lograr al menos un objetivo concreto de su campaña. Tras recorrer otros 100 km, llegó nuevamente a Tomave, donde recibió una nueva contraorden de Daza: debía cambiar nuevamente el rumbo y dirigirse a Tacna para reunirse con él. Con esta indicación culminaba la sucesión de contradicciones en la conducción militar de la $5^{\text {a }}$ División. De todos modos, la nueva orden no se cumplió nunca. Por un lado, Campero respondió que era imposible, dadas las condiciones de la tropa. Por otro, Daza fue derrocado y quedó fuera del mando. Comenzaba una etapa nueva de la historia militar y política de Bolivia.

Mientras tanto, el batallón Ayacucho y el escuadrón Méndez permanecían en las adyacencias de San Cristóbal y Canchas Blancas, en un ambiente de frustración por la

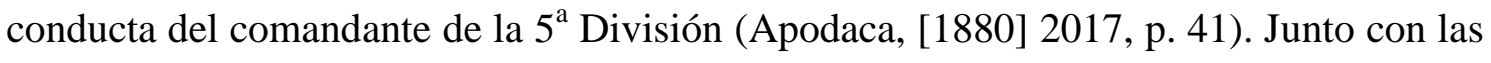
recurrentes descalificaciones hacia Campero, el ambiente reinante en los efectivos que quedaron en San Cristóbal se cargaba de incertidumbre y tensión debido a la constante llegada de espías, "indios", fugitivos, viajeros y desertores con noticias alarmantes. Junto con las malas noticias del curso principal de la guerra, se propagaban versiones de inminentes avances de tropas chilenas, justamente sobre las posiciones de estas fuerzas bolivianas. El 4 de noviembre el cronista anotó en su diario: "Al atardecer llegan unos 
indios de Huatacondo y Canchas Blancas que están en conexión con otros que operan en la retaguardia del enemigo. Importantes noticias traen sobre sus efectivos de artillería, caballería, infantería: son unos mil cuatrocientos" (Apodaca, [1880] 2017, p. 42).

El rumor sobre la presencia de mil cuatrocientos soldados chilenos cerca de Canchas Blancas, anotado por el coronel boliviano, es un registro trascendente. Se trata de la única referencia a ese número de efectivos en el libro publicado en 2017, y sobre la base de este testimonio el relato de Evo Morales se apoyó para afirmar la existencia del encuentro de Canchas Blancas como una batalla de grandes proporciones.

El análisis crítico de esta afirmación, siguiendo a Bauer ([1957] 1970), implica tensionarlo con la documentación disponible de esa época. Allí surge la inconsistencia, porque según el estado actual de las investigaciones sobre el tema, se puede afirmar que no era materialmente posible la presencia de tres batallones chilenos en ese lugar y en ese momento. El centro del esfuerzo militar de Chile estaba lejos de allí, $300 \mathrm{~km}$ al oeste. En efecto, el ejército chileno desembarcó en Pisagua el 2 de noviembre de 1879 y carecía de los medios militares para transportar 1.400 efectivos a lo largo de 300 kilómetros para situarlos allí dos días después, el 4 de noviembre (día anotado en el diario de Apodaca). Al contrario, las fuerzas chilenas se mantuvieron cerca del lugar de desembarco durante dos semanas, hasta que vencieron al ejército aliado en Dolores (19 de noviembre); posteriormente, se focalizaron en ocupar el puerto de Iquique. No hubo ningún desplazamiento de estas fuerzas hacia el este.

En este contexto, solo podían avanzar hacia Canchas Blancas las fuerzas asentadas en Calama, que apenas llegaban a trescientos hombres. Esta unidad militar podía realizar incursiones y librar combates de pequeña escala, como de hecho los hubo. En efecto, un mes más tarde, las fuerzas asentadas en Calama tuvieron oportunidad de entrar en acción. El 6 de diciembre de 1879, en el desfiladero de Tambillo, a 8 kilómetros de San Pedro de Atacama, se produjo el Combate de Tambillo, con triunfo del ejército de Bolivia en la Guerra del Pacífico (Diez de Medina, J. A., 9 de mayo de 2017). La fuerza encabezada por el coronel Rufino Carrasco, al mando de setenta bolivianos, superó al teniente Emilio Ferreira y sus 24 jinetes (Mellafe y Pelayo, 2016). La capacidad militar de las fuerzas chilenas en esa zona era muy limitada. 


\section{Figura $N^{\circ}$ 2: Acciones militares en la Guerra del Pacífico, nov.-dic. de 1879}

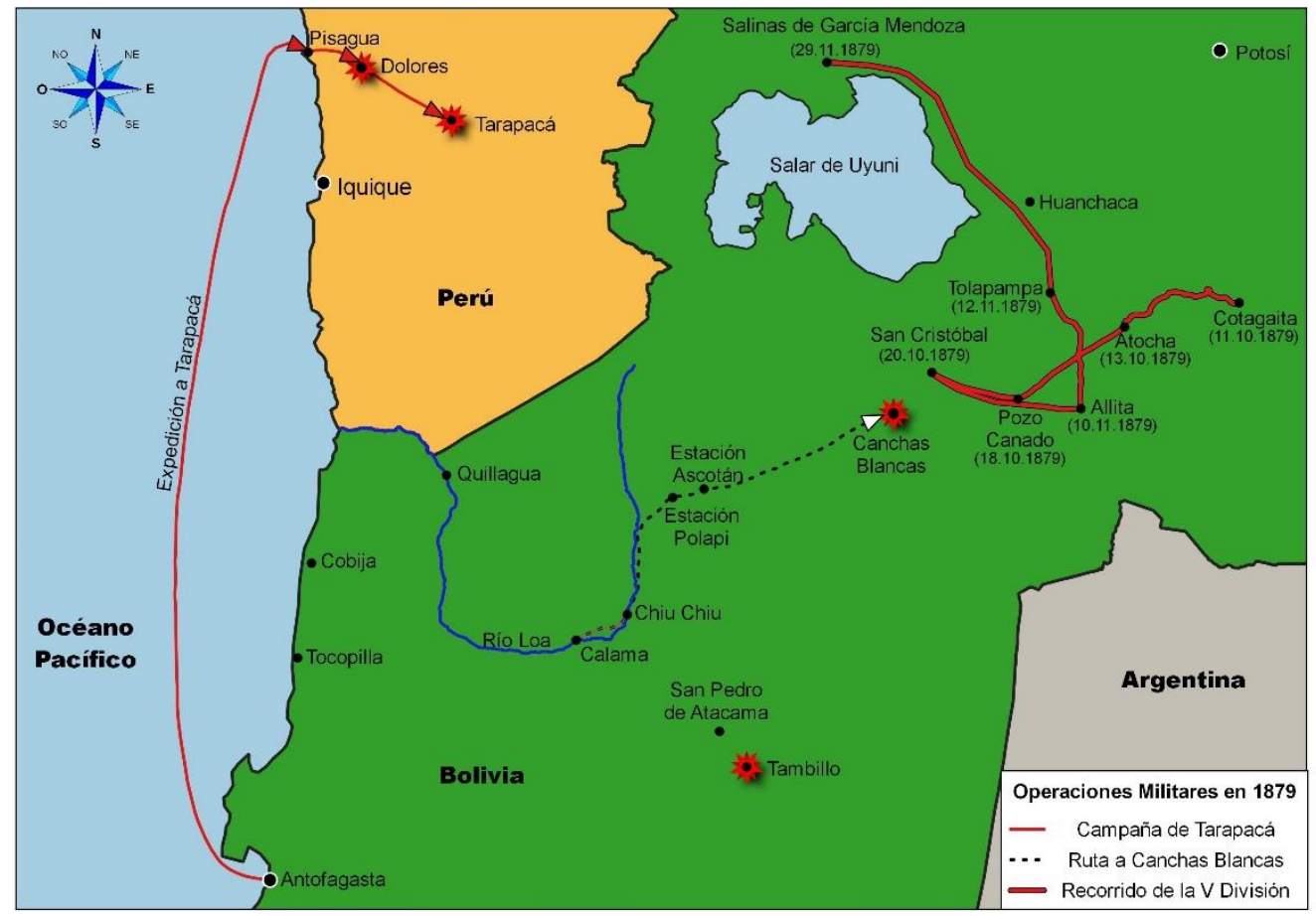

Fuente: mapa elaborado por Aldo Garrido a partir de datos publicados originalmente por fuentes oficiales.

Tal como muestran las figuras $\mathrm{N}^{\circ} 1$ y $\mathrm{N}^{\circ} 2$, en noviembre de 1879 las fuerzas chilenas en el teatro de operaciones cercano a Canchas Blancas solo podían nutrirse de los cuarteles de Calama, no así del cuerpo principal del ejército, afectada a la campaña de Pisagua y Tarapacá. Por lo tanto, en caso de tener buenas redes de información, el coronel Apodaca no hubiera dado crédito a los rumores propalados por los "indios" sobre la presencia de mil cuatrocientos soldados chilenos en Canchas Blancas. Ante la falta de información precisa, en el marco de la llamada "niebla de la guerra", los actores involucrados en la acción bélica se aferraban al rumor porque era lo único que tenían. Esta situación la vivían tanto los soldados como los oficiales, tal es el caso de Apodaca. Este coronel dio crédito a los rumores que le llegaron el 4 de noviembre porque, además, coincidían con las versiones que llegaban a sus oídos desde varios meses antes sobre una eventual invasión chilena (Apodaca, [1880] 2017, p. 29).

La crónica de Apodaca afirma que el hecho de Canchas Blancas fue un incidente confuso, ocurrido en la oscuridad de la noche. La presencia de artillería y caballería chilenas no surgió de la observación directa del coronel, sino de un testimonio indirecto posterior: "un herido, que luego murió, había relatado que allí tienen tropas, artillería y municiones, y posiciones bien hechas" (Apodaca, [1880] 2017, p. 54). El coronel boliviano menciona a un grupo de chilenos que llega a un mantial (Kocha) para tomar agua. No se indica la cantidad de tropas chilenas. Tampoco se menciona artillería. Son simplemente hombres y animales sedientos que, torpemente, se abalanzan hacia la 
fuente de agua, escena muy común en una guerra situada en el desierto. El relato indica también la hora del encuentro: las ocho de la noche.

En ese momento vino la orden. Se deslizaron silenciosamente los bolivianos y atacaron frontalmente, mientras que los indios ganan la retaguardia del enemigo para caerse sobre sus provisiones y destrozarles la cerca a pedradas aprovechando la noche. Los chilenos reciben la sorpresa, desmontados. Y (los bolivianos) caen en masa primero sobre la caballería. Los caballos inmediatamente son dispersados o tomados por los nuestros y llevados a buen recaudo, mientras que se sigue acometiendo a lo largo de las columnas chilenas, ya totalmente sorprendidas y confusas, pues con el primer plan, se dividió a los enemigos con una maniobra del ala izquierda que se encajó entre ellos mientras que los de la derecha atacaban su retaguardia y los indios y parte del (batallón) Ayacucho a su Estado Mayor. (Apodaca, [1880] 2017, p. 49)

El relato procura articular nociones contradictorias. Se mencionan maniobras militares, realizadas en la oscuridad de la noche, ambiente poco apto para desplazamientos sofisticados. Para explicar esta paradoja, el autor continúa:

Las contraseñas expresadas en quichua o términos chapacos hacían que en la oscuridad no haya confusión de los nuestros. Los sanlorenceños del (escuadrón de caballería) "Méndez" atacaron a cuchillo y machete limpio al enemigo y tomaron de inmediato la retaguardia más profunda. Desde el fondo de la batalla se sentía dolorosos ayes, cuando las tropas de San Lorenzo hundían sus filos en el vientre enemigo o en la garganta y, hasta se vio cuadros de luchas debajo del caballo, cuerpo a cuerpo y escucharse tremendas interjecciones chapacas. Trascurrió más de tres cuartos de hora y los tiros se fueron alejando y, conforme íbamos avanzando sobre el enemigo, de rato en rato aún se sentía el silbar de piedras de hondas indias dando caza a algún fugitivo. (Apodaca, [1880] 2017, p. 49)

La explicación del uso de lenguas indígenas permite comprender que se trataba de pequeños grupos en movimiento, que podían orientarse en la noche con el uso de una lengua identitaria compartida. También se mencionan algunos embates cuerpo a cuerpo, con armas blancas, y gritos de dolor de presuntos heridos. En la oscuridad de la noche, el combate solo duró 45 minutos (Apodaca, [1880] 2017, p. 50).

Terminada la acción, quedó el terreno en manos de las tropas bolivianas. ¿Qué apareció allí? El autor menciona simplemente municiones, fusiles, caballos y alimentos. No hay referencias a muertos, heridos ni artillería. Según las normas de la guerra y el contexto del siglo XIX, tras vencer a tu adversario era un deber del ejército victorioso otorgar una sepultura a amigos y enemigos. Apodaca no menciona tumbas. Tampoco hay rastros de ellas en la zona de Canchas Blancas. El investigador chileno histórico Mauricio Pelayo realizó una investigación de todas las muertes durante la Guerra del Pacífico: "Si hubiera 300 muertos en 'Canchas Blancas' (como se ha difundido recientemente en Bolivia), me daría cuenta. Esto no tiene justificación por ningún lado" (Pelayo cit. en Ochagavía, 30 de marzo de 2018, s. p.). 


\section{Tiempo de celebrar: brindis con singani}

El testimonio de Apodaca no se limitó a las acciones militares, sino que también se extendió a la vida cotidiana de los soldados: sus sensaciones y sus necesidades, sobre todo relacionadas con ropa y alimentos. En este ámbito resulta particularmente significativo el papel del singani dentro del diario del citado coronel, puesto que este es el trago simbólico de Bolivia y el buque insignia de su patrimonio agroalimentario.

El singani forma parte de la familia de los destilados andinos, junto con el pisco peruano y el pisco chileno. Se trata de un destilado elaborado a partir de uvas hispanocriollas, específicamente de la variedad moscatel de Alejandría. Igual que sus pares de Chile y Perú, el singani boliviano ha sido reconocido en su significado patrimonial y delimitado como denominación de origen por el Estado. Representa la primera denominación de origen de este país y se apoya en un largo proceso cultural.

El concepto singani proviene de la palabra "siwinga" o cortadera Sp. Se trata de una planta silvestre muy valorada por los campesinos bolivianos por ser fijadora de suelos; protege estos de los aluviones, de los desbordes de ríos y de otras formas de erosión. Los campesinos de Bolivia también la usan como material de construcción; con ella hacen mazos que se colocan en los aleros de las casas. La abundancia de estas plantas se expresa con el posfijo "ni", y de allí surgió la palabra "singani" para denominar una localidad donde estas plantas eran muy abundantes, situada en la provincia de NorCinti. Este pequeño paraje vitivinícola fue registrado en el Diccionario geográfico de la Sociedad Geográfica de Sucre (Sociedad Geográfica de Sucre, 1903).

Los campesinos bolivianos se dedicaron a cultivar la vid y elaborar aguardiente, el cual con el tiempo adoptó el nombre de la localidad y se comenzó a llamar singani. Historiadores bolivianos del vino y del singani han realizado extensas publicaciones para dar cuenta de la evolución de este destilado patrimonial desde el final de la Guerra del Pacífico hasta la actualidad (Aillón y Kirigin, 2013; Buitrago, 2014). Estos autores no alcanzaron a revisar la Memoria del Cnel. Ezequiel Apodaca, lo cual hubiera servido para fortalecer significativamente el relato del singani como patrimonio ancestral.

En efecto, el diario del coronel boliviano se dedicó muy especialmente a visibilizar, registrar y reconocer el papel del singani en los dramáticos momentos que vivió su patria durante las maniobras de la $5^{\text {a }}$ División. Los registros del militar sobre la presencia del patrimonio agroalimentario comenzaron en los primeros aprestos de la fuerza boliviana, cuando todavía se encontraba acantonada en Cotagaita.

Ahora que hemos llegado a Cotagaita tenemos todo. Tarija y Cinti y sobre todo el pueblo de Potosí y sus provincias, nos han regalado grandes cantidades de trigo, maíz, papas, okas, charqui, ganado en pie mayor y menor, pasa de uva, pasas de higo, despepitados, vinos, singanis y otros llegados de Cinti, Turuchipa y demás valles. (Apodaca, [1880] 2017, p. 20)

Con estas palabras, el oficial boliviano introducía en su diario la presencia de los alimentos y bebidas, especialmente del singani. En los meses posteriores, Apodaca 
mantuvo este interés y recurrentemente incluyó en su diario referencias al papel de este destilado en sus tropas. Particularmente importante era esta bebida en momentos de mayor tensión, cuando se requería cohesión máxima entre los oficiales y la tropa. Apodaca volvió a mencionar el singani en las maniobras realizadas por el batallón Ayacucho y por el escuadrón Méndez de caballería, dos meses más tarde:

El coronel Morales dispuso se repartiera un poco de trago (singani) en los yanbuis de los soldados o un yambui lleno de vino, cuando se tenga a la vista a los chilenos. Para ello llevamos las botijas con sigilo para que nadie se dé cuenta de su contenido y las guardamos. (Apodaca, [1880] 2017, p. 47)

Los usos del singani se incrementaban en forma proporcional a la tensión y la incertidumbre que envolvían a las tropas. A medida que los días corrían, la intranquilidad crecía con la llegada de rumores de eventuales batallones chilenos listos para aparecer, de un momento a otro, para invadir el sur de Bolivia y tomar Potosí. Esas versiones habían afectado el ambiente de los soldados bolivianos, y servía para construir imágenes de una eventual invasión. En este contexto, los oficiales y la tropa de las unidades afectadas a la seguridad del sur boliviano se sentían responsables de detener a un eventual invasor para proteger su país. Ese fue el sentido que le dieron al encuentro de Canchas Blancas. Inmediatamente después de terminada la acción militar, se produjo un emotivo encuentro entre oficiales y tropas, coronado, justamente, con un brindis con singani:

En los grupos de regreso está el Coronel Villarpando rodeado de los del Ayacucho, se sube a una especie de alturita y desea hablar a sus soldados, a quienes solo atina a decirles: "Soldaditos... queridos hijos míos... (un llanto profundo no lo deja hablar) y sigue: "Soldaditos, indiecitos queridos, ustedes han salvado a Potosí". Se baja de esa altura y se sienta a llorar en tal forma que hace llorar a todos... "Lloro de emoción" -decía- "lloro porque hemos ganado, hemos defendido la patria, desde aquí abandonados por ese Kuchi de Campero...". El Comandante Coronel Morales lo abrazó emocionado y juntamente conmigo y el Coronel Ayoroa lo llevamos hacia el socavón, donde le dimos agua fresca de un lluro, y luego una copa de singani. (Apodaca, [1880] 2017, p. 50).

Las fuentes documentales permiten discutir si las acotadas fuerzas chilenas acantonadas en Calama podían, efectivamente, realizar una invasión al sur de Bolivia. Es posible que esta acción haya sido poco verosímil, pero desde la perspectiva de las percepciones de los oficiales y tropas bolivianas, esa amenaza era real. Por lo tanto, ellos sentían que al detener en las tinieblas de la noche a las fuerzas chilenas, habían enfrentado un riesgo mayor. Los sentidos y las emociones de ese puñado de bolivianos estaban fuertemente activados por la niebla de la guerra. Y en ese momento de máxima tensión, se eligió la compañía de un producto típico identitario como el singani. Esta celebración no quedó acotada a la noche del 12 de noviembre, sino que se prolongó hasta el día siguiente.

Sale el Coronel Ayoroa, para ordenar se monte guardia en reemplazo de los que acaban de llegar del Méndez. Además, se dispone nuevos patrullajes. Al amanecer está aclarando lejos. Todos los Jefes están reunidos, charlando, nadie 
ha dormido, se ha prohibido fumar, encender fuego, pero en el túnel hondo detrás de una colina especie de morro están hirviendo muchas ollas, traídas de Tarija y Potosí con ponches para repartir a la tropa. Se envía las ollas a las posiciones. Se les reparte un yambui de rica bebida de singani. (Apodaca, [1880] 2017, p. 50)

El diario del oficial boliviano sirvió, de esta manera, como el primer registro conocido hasta ahora de la bebida emblemática de su país. Tal vez, sin saberlo, el jefe de Estado Mayor de la $5^{\text {a }}$ División fue el artífice de un registro llamado a visibilizar y fortalecer el patrimonio agroalimentario nacional. La delimitación de este aguardiente como denominaciones de origen se produjo un siglo más tarde, según el decreto 21.948 de 1988. De este modo se perfeccionó jurídicamente la denominación de origen del principal destilado patrimonial de Bolivia.

\section{Conclusión}

El libro Memoria del Cnl. Ezequiel Apodaca, editado por el Ministerio de Defensa de Bolivia en 2017 (que permaneció inédito desde 1880), incluye documentos de distinto valor historiográfico. El Parte de la batalla, elaborado por Lino Morales (pp. 72-78), presenta cuatro debilidades: en primer lugar, informa de un hecho de armas nocturno, lo cual debe interpretarse con precaución porque "los partes nocturnos son siempre exagerados" (Atkinson, 2016, p. 17); segundo, la falta de huellas de batalla en el lugar mismo de los hechos le resta verosimilitud; tercero, la evidencia documental muestra que las fuerzas armadas chilenas estaban muy lejos de ese lugar, pues se encontraban por entonces a $300 \mathrm{~km}$ al nordeste, aprestándose para librar la batalla de Dolores y tomar el puerto de Iquique; y cuarto, el Parte no fue considerado como fuente confiable por la historiografía boliviana, lo cual es otro indicador de la verosimilitud y autenticidad de un documento (Bauer, [1957] 1970).

En cambio, la parte sustancial de la publicación, el diario de Apodaca (pp. 16-66), sí resulta verosímil y puede considerarse fuente de valor histórico, al ser ponderado por la historiografía boliviana. Su verosimilitud y coherencia dice relación con el estado actual de los conocimientos sobre el tema. La riqueza de este documento permitirá múltiples abordajes para la historiografía. Por un lado, muestra el vigor de las fuerzas bolivianas, lo cual marca distancias con la imagen débil proyectada por la historiografía tradicional sobre la Guerra del Pacífico. Además, el documento entrega datos relevantes sobre comidas y bebidas de la época, lo cual puede despertar el interés de los estudiosos de la historia de la alimentación y el patrimonio agroalimentario. Particular relevancia adquiere sus referencias al singani, bebida emblemática de Bolivia. Por un lado, este diario brinda el primer registro documental de este destilado, y lo sitúa en un lugar de alto valor simbólico y ceremonial. En el marco de las grandes dificultades que presenta el estudio del patrimonio agroalimentario popular, debido al complejo acceso a las fuentes, el diario de Apodaca ofrece antecedentes de gran valor histórico para 
comprender los orígenes y la evolución de los destilados andinos, lo cual constituye un relevante acervo para desarrollar el valor simbólico de estas bebidas en el mercado.

Movido por el constante interés de visibilizar lo invisibilizado y cuestionar una visión sesgada de la historia, Evo Morales impulsó la publicación del libro en 2017 con la convicción de realizar un aporte significativo al fortalecimiento de la identidad de su país y de paso contribuir a la consolidación del orgullo nacional, pese al contexto adverso de pobreza y subordinación. El análisis crítico de la obra publicada muestra un resultado ambiguo. El documento no puede sustentar la tesis de la victoria de Canchas Blancas como esperaba Evo Morales, pero sí brinda aportaciones todavía más significativas, al consolidar la historia de la bebida emblemática de su país, buque insignia para la puesta en valor de su patrimonio agroalimentario.

\section{Referencias bibliográficas}

Aillón, E. y Kirigin, M. A. (2013). San Pedro: testigo de los tiempos. Por la ruta del singani en Bolivia. Oropeza: Archivo y Biblioteca Nacional.

Apodaca, E. ([1880] 2017). Memoria del Cnl. Ezequiel Apodaca. Potosí-CotagaitaCamino a Canchas Blancas 1879-1880. La Paz: Ministerio de Defensa. Estado Plurinacional de Bolivia.

Atkinson, R. (2014). Los cañones del atardecer. La guerra en Europa, 1944-1945. Barcelona: Crítica.

Atkinson, R. (2016). Introducción. En G. Patton, La guerra como la conocí (pp. 13-24). Málaga: Editorial Platea.

Barros Arana, D. (1880). Historia de la Guerra del Pacífico (2a ed.). Santiago: Editorial Andrés Bello.

Bauer, W. ([1957] 1970). Introducción al estudio de la historia (3 ${ }^{\mathrm{a}}$ ed.). Barcelona: Bosch.

Benavides Santos, A. ([1927] 1972). Historia compendiada de la Guerra del Pacífico (1879-84) (2 $2^{\mathrm{a}}$ ed.). Santiago: Editorial Francisco de Aguirre.

Boletín de la Guerra del Pacífico, 1879-1881. (1979). Santiago: Editorial Andrés Bello. Recuperado http://www.memoriachilena.gob.cl/archivos2/pdfs/MC0066573.pdf

Bulnes, G. (1911). Guerra del Pacífico. De Antofagasta a Tarapacá. Tomo I. Valparaíso: Sociedad Imprenta y Litografía Universo. Recuperado de http://www.memoriachilena.gob.cl/602/w3-article-8075.html

Buitrago, A. (2014). La vitivinicultura emergente en Bolivia y las oportunidades para el Singani. Rivar, 1(2), 90-102. 
Caivano, T. (1886). Historia de la guerra de América entre Chile, Perú y Bolivia. (1979). Lima: Biblioteca de Oficia.

Cam, L. E. (2017). El morro de Arica. La resistencia del periodismo peruano durante el cautiverio de Tacna y Arica. Lima: Fondo Editorial Escuela de Edición de Lima.

Carta geográfica: de las operaciones del ejército chileno en la guerra contra el Perú y Bolivia [material cartográfico] (¿1800?). Santiago: Lit. San Antonio. Recuperado de http://www.bibliotecanacionaldigital.gob.cl/bnd/632/w3-article-339784.html

Carrasco, R. (1879). Manifiesto del Coronel Rufino Carrasco sobre la espedicion al litoral boliviano en 1879. La Paz: Ministerio de Defensa. Estado Plurinacional de Bolivia. Recuperado de http://www.mindef.gob.bo/ mindef/sites/default/files/ediciones/Facsimil_Carrasco.pdf

Carrera, J. M. (1900). Diario militar del general don José Miguel Carrera. Santiago: Imprenta Cervantes.

Cofré León, C. y Stewart, D. (2020). Viña, alambiques y "veinticinco botijas de pisco". Alhué, 1717. Rivar, 7(20), 88-107. DOI: 10.35588/rivar.v7i20.4481

Concha, J. M. (2007). La política boliviana. Iniciativas del Ejecutivo chileno para una alianza estratégica con Bolivia (1879-1899). Santiago: Brickl Ediciones.

Choque Alanoca, E. (1998). El impacto de la guerra con Chile en Tacna 1879-1884. Tomo II ( $2^{\mathrm{a}}$ ed.). Tacna: Instituto de Ciencias Sociales.

Diez de Medina, J. A. (9 de mayo de 2017). Guerra del Pacífico: El combate de Tambillo. El Diario (Bolivia), Columna. Recuperado de https://www.opinionglobal.cl/guerra-del-pacifico-el-combate-de-tambillo/

El Litoral (23 de marzo de 1972). ¿Canchas Blancas? Una imaginaria batalla que no ha existido. El Litoral.

Escobari Cusicanqui, J. (1975). Historia diplomática de Bolivia. Tomo 2 ( $3^{\mathrm{a}}$ ed.). La Paz: Consejo Nacional de Educación Superior.

Espejo, G. ([1878] 1916). Crónica histórica de las operaciones del ejército de los Andes para la restauración de Chile en 1817. Buenos Aires: Librería La Facultad.

Eyzaguirre, J. (1963). Chile y Bolivia. Esquema de un proceso diplomático. Santiago: Editorial Zig-Zag.

Gómez-Cuevas, K., Delgado-Cruz, A. y Palmas-Castrejón, Y. (2020). Originalidad del tequila como símbolo de identidad mexicana. Percepción del turista-consumidor a partir de su exportación. Rivar, 7(21), 59-80. DOI: 10.35588/rivar.v7i21.4638

Gutiérrez, A. ([1914] 2012). La guerra de 1879. La Paz: Librería Editorial GUM. 
Gutiérrez, R., Gómez, S. y Guerrero, C. (1981). Historia del Ejército de Chile. Tomo V: Ocupación de Antofagasta y Campaña de Tarapacá (2 ${ }^{\mathrm{a}}$ ed.). Santiago: Estado Mayor General del Ejército.

Guzmán Escobari, A. (2015). Un mar de promesas incumplidas. La historia del problema marítimo boliviano (1879-2015). La Paz: Editorial Plural.

Ibarra Cifuentes, P. (2017). La guerra en cautiverio. Los prisioneros de la Guerra del Pacífico (1879-1884). Santiago: Legatum Editores.

Lacoste, P. (2017). El queso de Tafí del Valle y el despertar de la cultura del queso en Argentina. Idesia, 35(1), 87-95. DOI: 10.4067/S0718-34292017005000004

Lacoste, P. (2018). Guerra del Pacífico. La batalla del pisco. Santiago: RIL Editores.

Lacoste, P., Castro, A., Briones, F., Cussen, F., Soto, N., Rendón, B., Mujica, F., Aguilera, P., Adunka, M., Núñez, E. y Cofré, C. (2015). Vinos típicos de Chile: ascenso y declinación del Chacolí (1810-2015). Idesia, 33(3), 97-108.

Lagos Carmona, G. ([1966] 1981). Historia de las fronteras de Chile. Los tratados de límites con Bolivia (2 $2^{\mathrm{a}}$ ed.). Santiago: Editorial Andrés Bello.

López, J. (1980). Historia de la guerra del guano y el salitre. (1980). Lima: Editorial Universo.

López Martínez, H. (1989). Guerra con Chile. Episodios y personajes 1879-1885. Lima: Librería Editorial Minerva.

Lora, J. F. W. (1981). La guerra 1879-1979. Chile-Bolivia-Perú ( $3^{\text {a }}$ ed.). Lima: Ediciones Juan Gutemberg.

Mellafe, R. y Pelayo, M. (2016). La Guerra del Pacífico en imágenes, relatos y testimonios. Santiago: Editorial Legatum.

Morales, E. [evoespueblo] (28 de marzo de 2018). Hoy rememoramos la Batalla de Canchas Blancas, en la que 500 soldados de la Quinta División, junto a campesinos e indígenas, derrotaron a 1.400 soldados del ejército chileno. Esa gesta heroica frustró el plan de Chile, de tomar por las armas las minas de Potosí. [Tweet]. Recuperado de https://twitter.com/evoespueblo/ status/979075486482616321?s=19

Ochagavía, D. (30 de marzo de 2018). "Canchas Blancas", la batalla que conmemoró Evo y que historiadores dicen que no existió. El Mercurio, Cuerpo C, s. p. Recuperado de http://images.elmercurio.com/MerServerContents /PDFSlow/2018/mar/30/MERSTNA001CC3003.pdf

Parodi, D. (23 de abril de 2018). ¿La batalla de Canchas Blancas realmente sucedió? El Comercio, sección Actualidad, s. p. Recuperado de https://elcomercio.pe/ eldominical/actualidad/tradicion-inventada-noticia-514316-noticia/

Parvex, G. (2014). Un veterano de tres guerras. Santiago: Salesianos Impresores S.A. 
Paz Soldán, M. (1884). Narración histórica de la guerra de Chile contra Perú y Bolivia. Buenos Aires: Imprenta y Librería de Mayo.

Pelayo, M. (2019). Los que no volvieron. Los muertos en la Guerra del Pacífico. Santiago: RIL Editores.

Pueyrredón, M. ([1863] 1947). Memorias inéditas del coronel Manuel A. Pueyrredón. Historia de mi vida. Campañas del Ejército de los Andes. Buenos Aires: Kraft.

Querejazu Calvo, R. (1979). Guano, salitre, sangre: historia de la Guerra del Pacífico ( $2^{\mathrm{a}}$ ed.). La Paz: Editorial Los Amigos del Libro.

Querejazu Calvo, R. (1982). Guerras del Pacífico y del Chaco: similitudes y diferencias. La Paz: Editorial Los Amigos del Libro.

Ríos Gallardo, C. (1963). Chile y Bolivia definen sus fronteras 1842-1904. Santiago: Editorial Andrés Bello.

Ruz, F. (1980). Rafael Sotomayor Baeza, el organizador de la victoria. Santiago: Editorial Andrés Bello.

Sanhueza, C. y Gundermann, H. (2009). Capitales, Estado rentista y cambio social atacameño en las regiones interiores de Antofagasta (1879-1928). Universum (Talca), 24(1), 218-246. DOI: 10.4067/S0718-23762009000100013

Sequeira, C. y Montes Leal, P. (2020). The Brand as Value Production. From the Trademark to the Designation of Origin of Wines from the Douro Demarcated Region. Rivar, 7(21), 136-157. DOI: 10.35588/rivar.v7i21.4642

Sociedad Geográfica de Sucre (1903). Diccionario geográfico del Departamento de Chuquisaca. Sucre: Imprenta Bolívar.

Togores, J. R., Parga Dans, E. y Diz, C. (2020). Patrimonios y culturas del vino en riesgo de desaparición: el caso de As Adegas do Viño do País (Betanzos, Galicia). Rivar, 7(21), 33-58. DOI: 10.35588/rivar.v7i21.4637

Zambrana, E. e Inarra, L. (coords.) (2011). Facetas de la controversia con Chile. La Paz: Grupo Editorial Kipus. 